\title{
Hot Tearing of Sand Cast Mg-5 wt.\% Y-4 wt.\% RE (WE54) Alloy
}

\author{
Jilin LI, Rongshi CHEN ${ }^{\dagger}$, Yuequn MA and Wei KE \\ 110016, China \\ [Manuscript received 18 April 2013, in revised form 2 September 2013] \\ (C) The Chinese Society for Metals and Springer-Verlag Berlin Heidelberg
}

State Key Laboratory for Corrosion and Protection, Institute of Metal Research, Chinese Academy of Sciences, Shenyang

\begin{abstract}
Hot tearing is a common and severe defect occurring during solidification of castings. The rational understanding of hot tearing formation mechanism is beneficial to the foundry process design. In the present research, a new developed instrumented "CRC" equipment was applied in characterization of hot tearing in sand cast Mg-5 wt.\% Y-4 wt.\% RE (WE54) alloy with and without Zr addition. Microstructure observation and thermal analysis were carried out to help analyzing the results. The results showed that hot tearing onset occurs at a relatively low solid fraction $\left(f_{\mathrm{s}}\right)$ in WE54 alloy sand castings, which indicates the participation of remaining liquid during hot tearing formation. Microstructure observation of the hot tearing surface also proves the liquid film existence between solidifying dendrites. The contraction strain caused by casting solidification induces the flowing of remaining liquid between solidifying dendrites and results in formation of interdendritic liquid films. These liquid films are separated by sufficient contraction stress and form hot cracks. The addition of $\mathrm{Zr}$ in WE54 alloy significantly refines the alloy microstructure and increases the solid fraction at hot tearing onset, both of which result in increasing of the fracture stress of interdendritic liquid film. Thus the hot tearing susceptibility of WE54 alloy is weakened by $\mathrm{Zr}$ addition.
\end{abstract}

\section{KEY WORDS: Mg-5 wt.\% Y-4 wt.\% RE (WE54) magnesium alloy; Sand cast; Hot tearing} defect; Instrumented "CRC"

\section{Introduction}

Magnesium alloys containing rare earth elements (RE) have received considerable interest in recent years due to their higher mechanical strength and better heat-resistance performance than those without RE additions ${ }^{[1-3]}$. Among them, Mg-5\% Y-4\%RE (WE54) magnesium alloy is a high strength sand casting magnesium alloy for applications at temperatures up to $300{ }^{\circ} \mathrm{C}$, which is of great interest to engineers of aerospace industry. However, the production of WE54 alloy castings in aerospace industry is significantly puzzled by casting defects such as hot tearing and shrinkage porosity formed during casting solidification. Since casting has been the dominant manufacturing process for magnesium components ${ }^{[4]}$, the rational understanding of formation mechanism of these

\footnotetext{
† Corresponding author. Prof., Ph.D.; Tel.: +86 2423926646 ; Fax: +86 24 23894149; E-mail address: rschen@imr.ac.cn (Rongshi CHEN)
}

DOI: $10.1007 / \mathrm{s} 40195-013-0230-9$ casting defects is needed in order to provide basically theoretical supports for design of pouring and feeding systems. However, to the best knowledge of the authors, the WE54 alloy has not been investigated in terms of castability considering the casting defects of shrinkage porosity and hot tearing.

Hot tearing is a common and severe defect which forms during solidification procedure of castings and it is perhaps the pivotal issue defining an alloy's castability. Thus the formation mechanism of hot tearing defect has attracted great attention of researchers, and various research methods have been developed during the study of hot tearing defect in steel and $\mathrm{Al}$ alloys, including semi-solid tensile test ${ }^{[5,6]}$, neutron diffraction technique ${ }^{[7]}$, X-ray micro-tomography ${ }^{[8,9]}$, and the most frequently used "CRC" (constrained rod casting) method ${ }^{[10-12]}$. However, the hot tearing behavior was only characterized qualitatively using these methods. In order to investigate hot tearing behavior in detail, an instrumented "CRC" method was recently developed by adding stress and temperature monitoring system on traditional "CRC" mold ${ }^{[13-18]}$. 

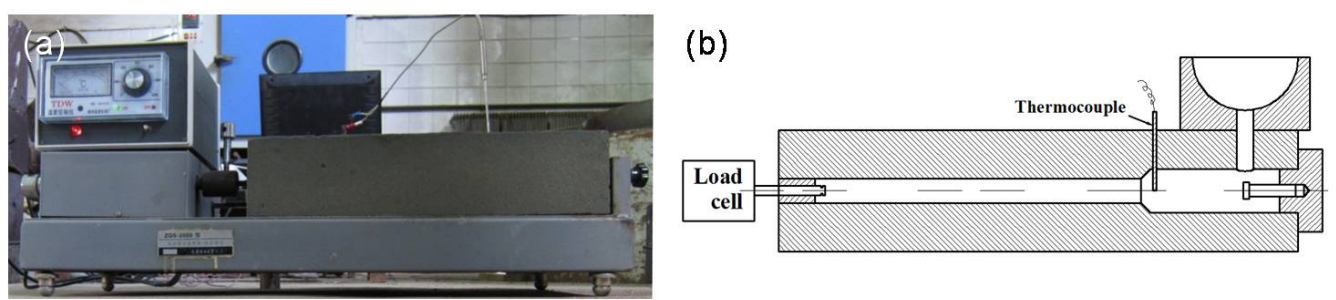

(c)
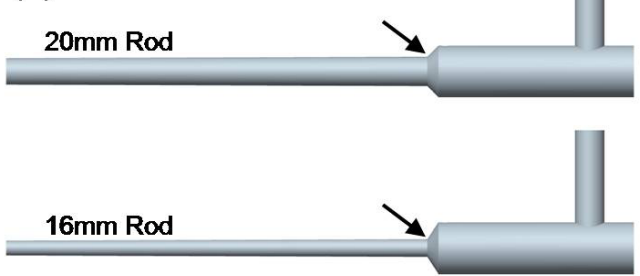

Fig. 1 Images showing the photo of instrumented "CRC" device (a), the schematic diagram of instrumented "CRC" device (b) and the different rod castings applied in the present research (arrows heading to the stress concentration positions during solidifying) (c)

With the instrumented "CRC" equipment, the stress and temperature variations during casting solidification were monitored, and the onset of hot tearing defect can be detected by the characteristic points on the stress-time curve. Then the onset temperature and fracture stress of hot tearing defect was determined, which benefited a lot to deep understanding of hot tearing behavior. Li et al. ${ }^{[14]}$ investigated the effect of $\mathrm{Y}$ on hot tearing behavior of $\mathrm{Al}-5 \mathrm{wt} . \% \mathrm{Cu}$ alloy using this technique, and found that the addition of Y refined the microstructure of Al-5 wt. $\% \mathrm{Cu}$ alloy, and decreased its hot tearing susceptibility. This technique was also used in the research of hot tearing behavior of magnesium alloys. Wang et al. ${ }^{[16]}$ investigated the hot tearing behavior of sand cast AZ91 alloy using similar method. It was found that hot tearing onset occurred at solidus temperature, and the hot tearing onset was induced by rapid solidification contraction caused by eutectic reaction occurring in remaining liquid. The technique was also applied in the research of hot tearing of ternary $\mathrm{Mg}$-Al-Sr alloys by Cao et al. ${ }^{[17,18]}$, who determined the solid fraction at hot tearing onset by combining the onset temperature and the $T-f_{s}$ (temperature-solid fraction) results acquired from thermodynamic calculation. And it was reported that the hot tearing onset occurs at solid fractions of 0.7-0.8 in Mg-Al-Sr alloy castings, which was lower than traditionally believed value ${ }^{[19]}$. However, due to uncertainty of thermodynamic calculation, the reported data of hot tearing onset solid fraction is still required to be confirmed by experimental measurement. One way to confirm the result is to couple measured hot tearing temperatures with measured, instead of calculated $T-f_{\mathrm{s}}$ data ${ }^{[17]}$.

In the present research, the onset temperature of hot tearing defect in sand cast WE54 alloy with and without $\mathrm{Zr}$ addition was determined using newly de- veloped instrumented "CRC" equipment. And the $T-f_{\mathrm{s}}$ data was measured by a detailed analysis of cooling curves ${ }^{[20]}$ recorded during alloy solidification. Combining the results of onset temperature and $T-f_{\mathrm{s}}$ data, the solid fraction at hot tearing onset was determined. Besides, the microstructure of hot tearing defect was observed by OM and SEM in order to understand the formation procedure of hot tearing defect. Then the effects of $\mathrm{Zr}$ on hot tearing behavior of WE54 alloy was discussed based on comparison of testing results obtained from sand cast WE54 alloy with and without $\mathrm{Zr}$ addition.

\section{Experimental Procedures}

The alloys were prepared from high purity $\mathrm{Mg}$ (99.95\%), Gd (99\%), Y (99\%), Nd (99\%) and/or a $\mathrm{Mg}-30 \mathrm{Zr}$ (wt.\%) master alloy by melting them in an electric resistance furnace under protection with an anti-oxidizing flux. The melt was poured into the sand mould of the instrumented "CRC" device shown in Fig. 1(a) and (b) at about $780{ }^{\circ} \mathrm{C}$ to cast the constrained rod castings shown in Fig. 1(c). The actual chemical composition of the alloy was determined by using inductively coupled plasma atomic emission spectroscopy (ICP) and listed in Table 1.

The structure of the instrumented "CRC" device used in the present research is shown in Fig. 1(a), which consists of a "CRC" sand mould and a data acquisition system for temperature and stress measurement attached with the mould. The device worked on similar principle with devices applied by Wang et $a l .{ }^{[16]}$ and Cao et al. ${ }^{[17,18]}$. Due to the stress concentration at the position marked with arrows in Fig. 1(c), hot tearing defect tends to form at this position. So the temperature and stress variations of this position were measured by a K-type thermocouple and a CL-YB-13T/200kg stress sensor and recorded by 
Table 1 Chemical composition of the experimental alloys (wt. \%)

\begin{tabular}{cccccc}
\hline Alloy & Y & Nd & Gd & Zr & $\mathrm{Mg}$ \\
\hline Zr-containing WE54 alloy & 5.02 & 1.92 & 2.13 & 0.45 & Bal. \\
Zr-free WE54 alloy & 5.10 & 1.91 & 2.03 & - & Bal. \\
\hline
\end{tabular}

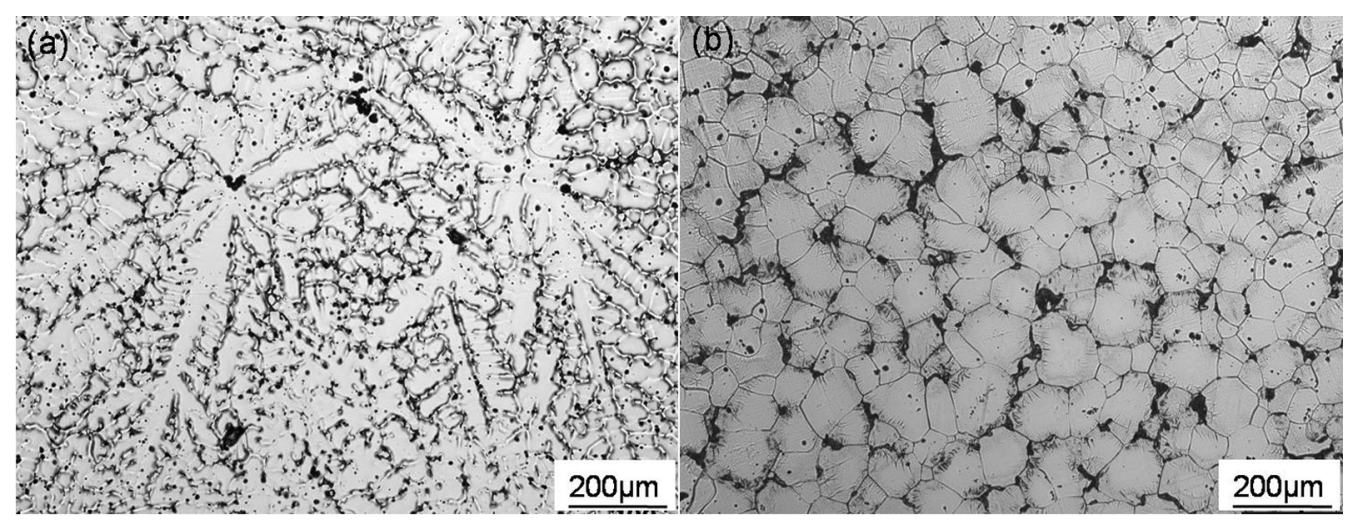

Fig. 2 The as-cast microstructures of Zr-free WE54 alloy (a) and Zr-containing WE54 alloy (b)

the computer. In order to confirm the reliability of the test results, the tests were carried out using different casting rods with diameters of $16 \mathrm{~mm}$ and $20 \mathrm{~mm}$, respectively. Besides, the cooling curves of the alloys were measured by remelting and solidifying the alloy in a steel crucible. The alloy melt was solidified at a cooling rate of approximately $1 \mathrm{~K} / \mathrm{s}$, which was similar to the cooling rate of rod castings in the "CRC" sand mould. Then the $T-f_{\mathrm{s}}$ curves of the alloys were calculated from their cooling curves using the method proposed by Thompson et al. ${ }^{[20]}$.

\section{Results}

\subsection{Microstructure observation of hot cracks}

As proved in previous studies, zirconium and magnesium have the same type of crystal structure and almost identical lattice constants (discrepancy $<1.3 \%$ ), which make $\mathrm{Zr}$ a perfect nucleating agent in magnesium alloys that are not alloyed with aluminum ${ }^{[21]}$. Thus the as-cast microstructure of WE54 alloy is found to be significantly refined after $\mathrm{Zr}$ addition, as shown in Fig. 2.

The hot tearing susceptibility of WE54 alloy is also affected by $\mathrm{Zr}$ addition. Fig. 3 shows the microstructure observed on the longitudinal section of the rod castings at the hot tearing position, where a totally ruptured hot tearing defect is detected in $\mathrm{Zr}$ free WE54 alloy castings, while only tiny hot cracks are observed in Zr-containing WE54 alloy castings. In the Zr-free castings, ribbon-shaped secondary phase is observed in the hot tearing district, which is marked with black arrows in Fig. 3(a). These ribbon-shaped secondary phases form through interdendritic liquid flowing before hot tearing onset. After hot tearing onset, the hot cracks continue to propagate along the liquid film, as shown in Fig. 3(b). Similar phenomena are also observed in Zr-containing WE54 alloy cast- ings as shown in Fig. 3(c) and (d).

In addition, the hot tearing surface of Zr-free alloy was observed by SEM and the fracture characteristics are shown in Fig. 4(a) and (b). It is found that the hot tearing surface is coated with liquid film, and the tearing ridge of liquid film is also observed and shown in Fig. 4(b). This indicate that a significant amount of interdendritic liquid is still present when hot tearing onset occurs, and the hot tearing defect forms through tearing of interdendritic liquid film under contraction stress.

\subsection{Onset of hot tearing defect}

The onset of hot tearing defect is investigated through measurements of hot tearing onset temperature and $T-f_{\mathrm{s}}$ data. Firstly, the onset temperature of hot tearing defect was measured by instrumented "CRC" method. And the results are shown in Fig. 5. As seen in the temperature and load curves in Fig. 5, the measured contraction load increases gradually as the temperature decreases at the first stage of solidification. And then a load platform is detected as marked with arrows on the stress curves, which represents the onset of hot tearing defect. Thus the onset temperature is determined by analyzing the temperature-stress-time curves, as shown in Fig. 5.

Fig. 5(a) and (b) show the onset temperature of hot tearing defect in Zr-free WE54 alloy. It is found that hot tearing onset occurs at $612.2{ }^{\circ} \mathrm{C}$ and $614.3^{\circ} \mathrm{C}$ in the $20 \mathrm{~mm}$ and $16 \mathrm{~mm}$ rods, respectively. Besides, considering the cross section area of the constrained rod castings, the contraction stress at the moment of hot tearing onsetting is determined to be about $0.5 \mathrm{MPa}$ in both the tests of Zr-free WE54 alloy. And the hot tearing onset occurs at about $590{ }^{\circ} \mathrm{C}$ in Zr-containing WE54 alloy castings under contraction stress of about 1.0 MPa, as shown in Fig. 5(c) and (d). 

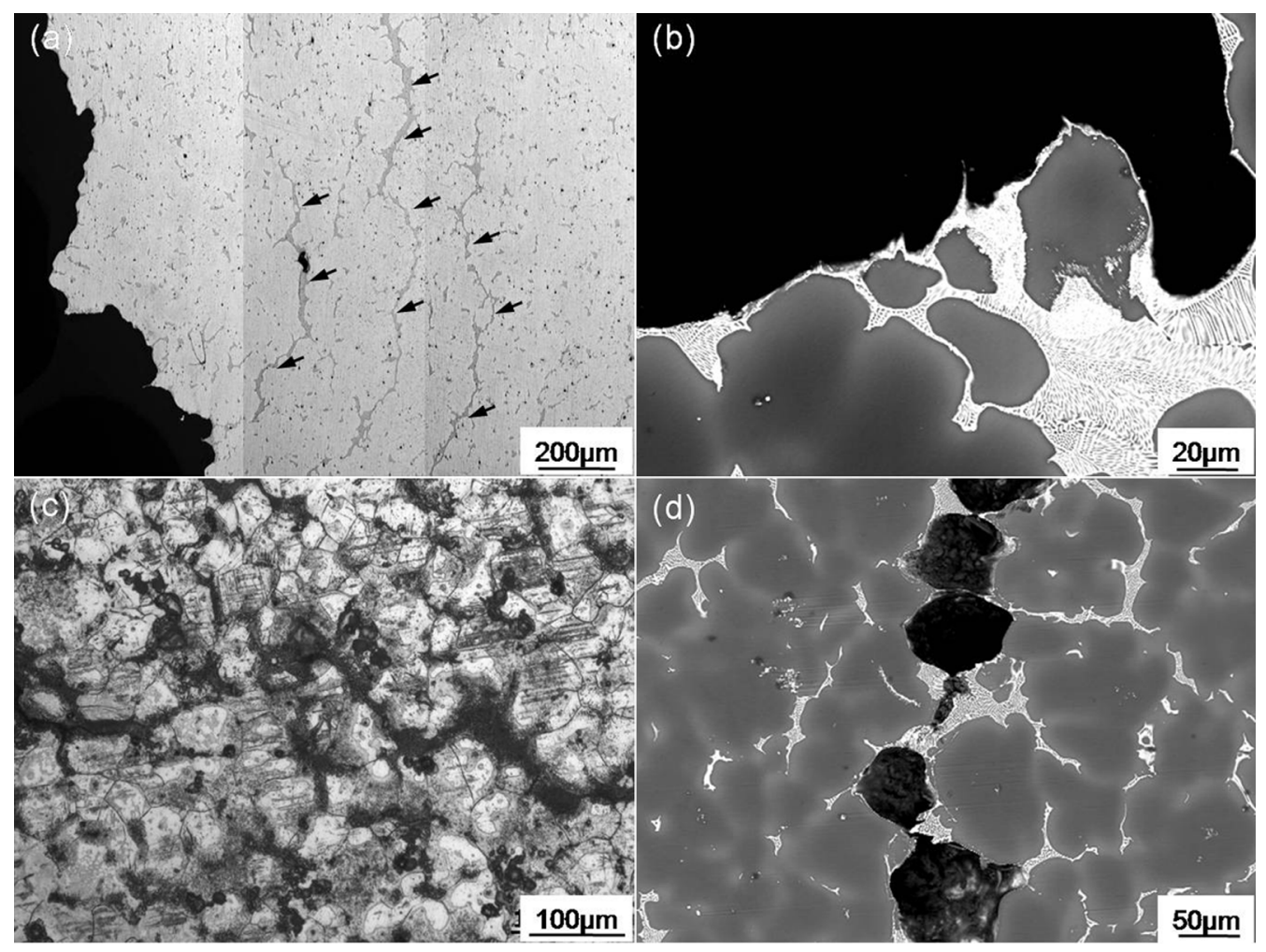

Fig. 3 Microstructure of longitudinal section of the hot tearing surface: (a,b) totally ruptured hot tearing defect in Zr-free WE54 alloy; (c,d) tiny hot cracks in Zr-containing WE54 alloy

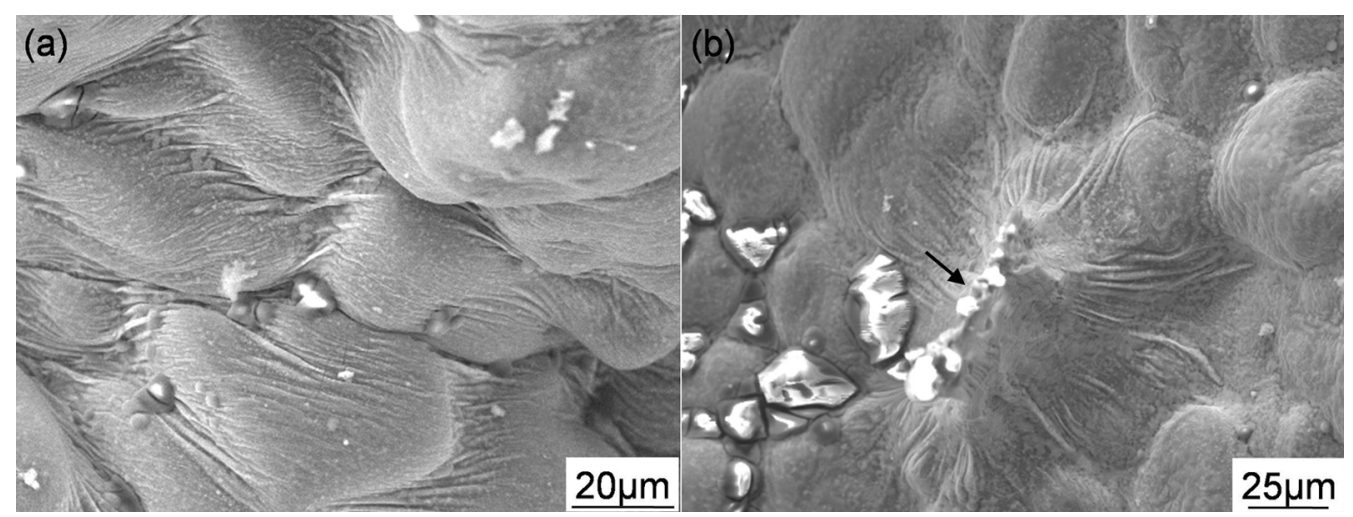

Fig. 4 Microstructure of the hot tearing surface in Zr-free WE54 alloy: (a) interdendritic liquid film; (b) tearing ridge of liquid film (marked with black arrow)

Then the $T-f_{\mathrm{s}}$ data of Zr-free WE54 alloy and Zrcontaining WE54 alloy were measured through a detailed analysis of their cooling curves and the results are shown in Fig. 6. According to previous work ${ }^{[20]}$, the solid fraction can be determined by calculating the area between the first derivative curve and the baseline shown in Fig. 6(a) and (b). In the present work, the base lines were estimated by curve fitting the $T-f_{\mathrm{s}}$ data below the solidus temperature and above the liquidus temperature. The $T T-f_{\mathrm{s}}$ curves of Zr-free alloy and Zr-containing alloy are plotted respectively in Fig. 6(c). Combining the results of onset temperature and $T-f_{\mathrm{s}}$ data, the solid fraction at hot tearing onset is determined and shown on
$T-f_{\mathrm{s}}$ curves in Fig. $6(\mathrm{c})$. The results show that hot tearing defect onset occurs at rather low solid fraction of 0.47 in Zr-free WE54 alloy castings, and the solid fraction at hot tearing onset $\left(f_{\mathrm{s}, \text { crack }}\right)$ increases to 0.74 after $\mathrm{Zr}$ addition. No matter $\mathrm{Zr}$ added or not, it is reasonable to speak that a significant amount of interdendritic liquid is still present in the solidifying alloy at the moment of hot tearing onset during sand casting solidification.

The above experimental results are summarized in Table 2, where the effects of $\mathrm{Zr}$ addition on hot tearing behavior of WE54 alloy are seen obviously. After Zr addition, the grain size $(d)$ of WE54 alloy decreases since the microstructure is significantly refined, the 

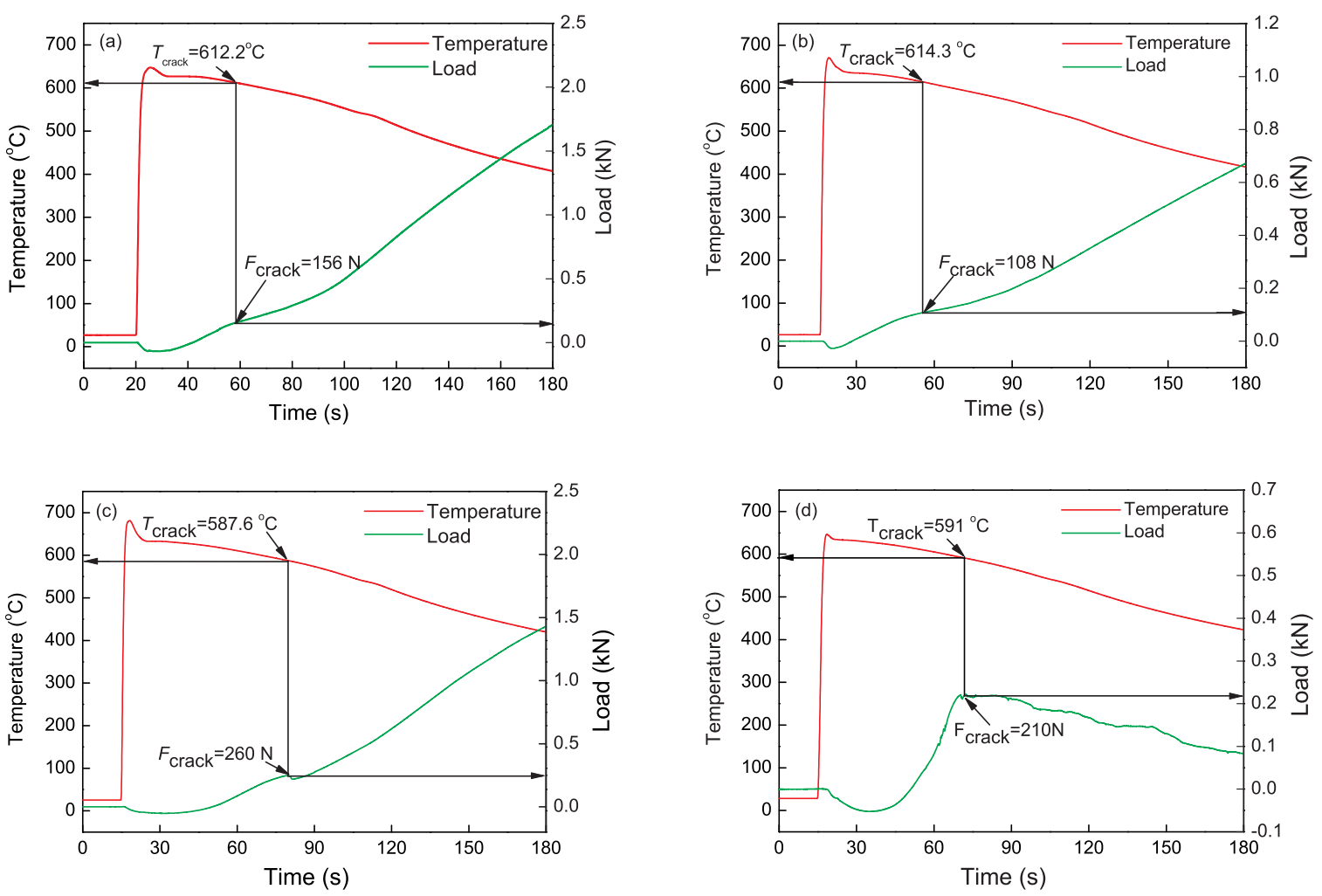

Fig. 5 The temperature-stress-time curve obtained from instrumented "CRC" experiment: (a) Zr-free WE54 alloy, $20 \mathrm{~mm}$ rod; (b) Zr-free WE54 alloy, $16 \mathrm{~mm}$ rod; (c) Zr-containing WE54 alloy, $20 \mathrm{~mm}$ rod; (d) Zrcontaining WE54 alloy, $16 \mathrm{~mm}$ rod

Table 2 Summary of the hot tearing behavior of WE54 alloy with and without Zr addition

\begin{tabular}{cccccc}
\hline Alloy & Microstructure & Rod diameter $(\mathrm{mm})$ & $F_{\text {crack }}(\mathrm{N})$ & $\sigma_{\text {crack }}(\mathrm{MPa})$ & $f_{\text {s,crack }}$ \\
\hline Zr-containing WE54 alloy & Fine grains & 20 & 260 & 0.83 & 0.74 \\
& & 16 & 210 & 1.04 & 0.74 \\
\hline Zr-free WE54 alloy & Coarse dendrites & 20 & 156 & 0.49 & 0.47 \\
& & 16 & 108 & 0.53 & 0.47 \\
\hline
\end{tabular}

$f_{\mathrm{s}, \text { crack }}$ increases from 0.47 to 0.74 . Moreover, the contraction stress under which hot tearing onset occurs $\left(\sigma_{\text {crack }}\right)$ increases from about $0.5 \mathrm{MPa}$ to about 1.0 $\mathrm{MPa}$, which suggests that the hot tearing susceptibility of WE54 alloy is weakened by $\mathrm{Zr}$ addition.

\section{Discussion}

\subsection{Hot tearing formation mechanism}

As shown in Table 2 , the $f_{\mathrm{s}, \text { crack }}$ during sand casting estimated in the present research is 0.47 in $\mathrm{Zr}$-free WE54 alloy and 0.74 in Zr-containing WE54 alloy, which is relatively lower compared with previously reported onset $f_{\mathrm{s}}$ of $0.78-0.85$ in metal mould cast $\mathrm{Mg}$ $x \mathrm{Al}-1.5 \mathrm{Sr}$ alloys ${ }^{[18]}$. This is possibly due to the relatively lower cooling rate of the alloys at hot spots during sand casting process compared with metal mould casting. As the alloy solidifies at a lower speed during sand casting process, a significant amount of interdendritic liquid still exists when hot tearing onset occurs at hot spots which were the latest solidified locations in sand castings. Thus it is reasonable to speak that liquid films surrounding the solidifying dendrites determines the mechanical behavior of semi-solid alloy at hot spots. As hot tearing defect forms at hot spots of sand castings, it is believed that hot tearing defect onset occurs through tensile fracture of semi-solid alloy.

According to research of Lahaie et al. ${ }^{[22]}$, the microstructure of the semisolid material is shown in Fig. 7(a), and the idealized 2-D view along $A-A$ plane of Fig. 7(a) is shown in Fig. 7(b), in which the solidifying dendrites are surrounded by uniformly distributed interdendritic liquid. Then the hot tearing formation procedure in WE54 alloy sand castings can be schematically described by Fig. 7(b), (c) and (d). During the casting solidification, the contraction deformation of the constrained rod casting is mainly counterbalanced by tension deformation at hot spots (positions marked by arrows in Fig. 1(c)), where the tension deformation is mainly achieved by flow- 

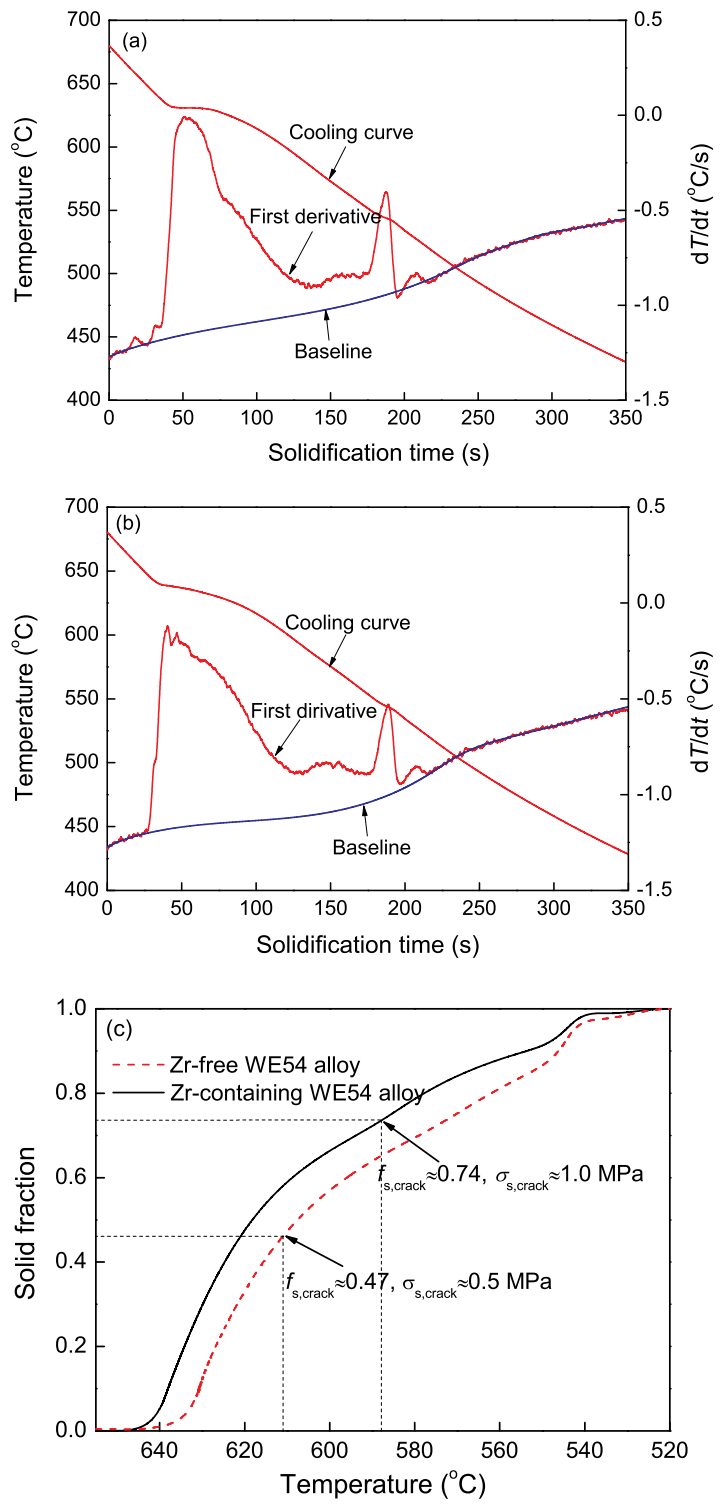

Fig. 6 Cooling curve analysis results of the investigated alloy: (a) Zr-free WE54 alloy; (b) Zr-containing WE54 alloy; (c) the $T-f_{\mathrm{s}}$ curves (arrows heading to the onset points of hot tearing defect)

(a)

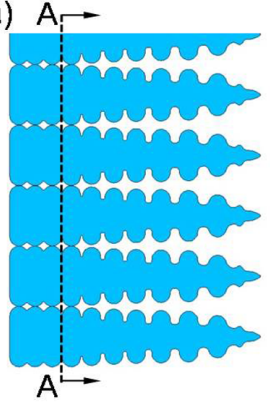

(b)

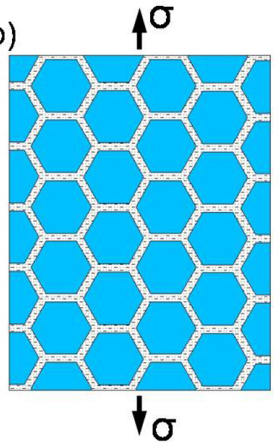

ing of interdendritic liquid. And the flowing of interdendritic liquid results in the formation of ribbonshaped interdendritic liquid films as marked with arrows in Fig. 7(c). Since liquid is incapable of plastic deformation, the tension deformation allowed at hot spots is very limited. When the tension strain reaches the maximum value, the contraction stress begin to increase until the interdendritic liquid films are separated under a contraction stress of $\sigma_{\text {crack }}$ and form hot cracks, as shown in Fig. 7(d). And the un-separated liquid film solidifies and forms ribbonshaped secondary phase near hot tearing defect, as detected in the microstructure of hot tearing defect shown in Fig. 3(a) and (c).

\subsection{Effects of $\mathrm{Zr}$ addition}

As mentioned above, the mechanical behavior of solidifying alloy is determined by liquid films surrounding the solidifying dendrites, and hot cracks form through tearing of interdendritic liquid films. So the contraction stress under which hot tearing onset occurs $\left(\sigma_{\text {crack }}\right)$ can be determined theoretically by calculating the fracture stress of interdendritic liquid film $\left(\sigma_{\text {lf }}\right)$. As schematically shown in Fig. 8(a), $\sigma_{\text {crack }}$ is determined by surface tension $\gamma$ and liquid film thickness $b$ through Eq. (1) according to previous work ${ }^{[23]}$ :

$$
\sigma_{\text {crack }}=\sigma_{\text {lf }}=2 \gamma / b
$$

Besides, as shown in Fig. 7(b), the 2-D cut of the semi-solid microstructure of alloy is composed of elementary units schematized in Fig. 8(b), according to which the liquid film thickness $b$ is represented as a function of grain size $d$ and solid fraction $f_{\mathrm{s}}^{[22]}$ :

$$
b=\frac{\sqrt{3}}{2} d \cdot\left(\frac{1-\sqrt{f_{\mathrm{s}}}}{\sqrt{f_{\mathrm{s}}}}\right)
$$

Finally, $\sigma_{\text {crack }}$ was represented by Eq. (3) after substituting Eq. (2) into Eq. (1):

$$
\sigma_{\text {crack }}=\frac{4 \gamma \sqrt{f_{\mathrm{s}}}}{\sqrt{3}\left(1-\sqrt{f_{\mathrm{s}}}\right) d}
$$

(c)

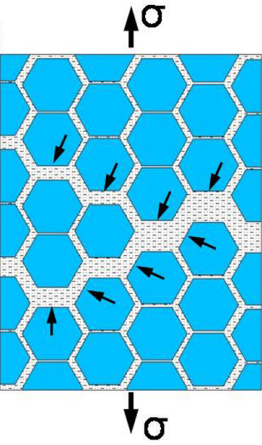

(d)

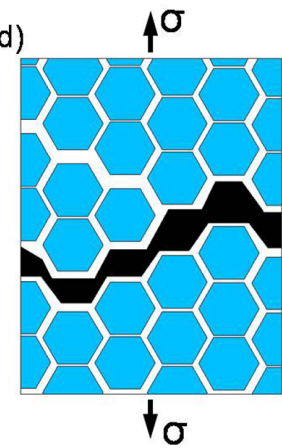

Fig. 7 Idealized mushy-zone microstructure of alloy and schematic diagram of hot tearing formation procedure: (a) idealized mushy-zone microstructure of solidifying alloy; (b) idealized 2-D view along A-A plane in Fig. 7(a); (c) interdendritic liquid films marked by the arrows; (d) hot tearing defect 

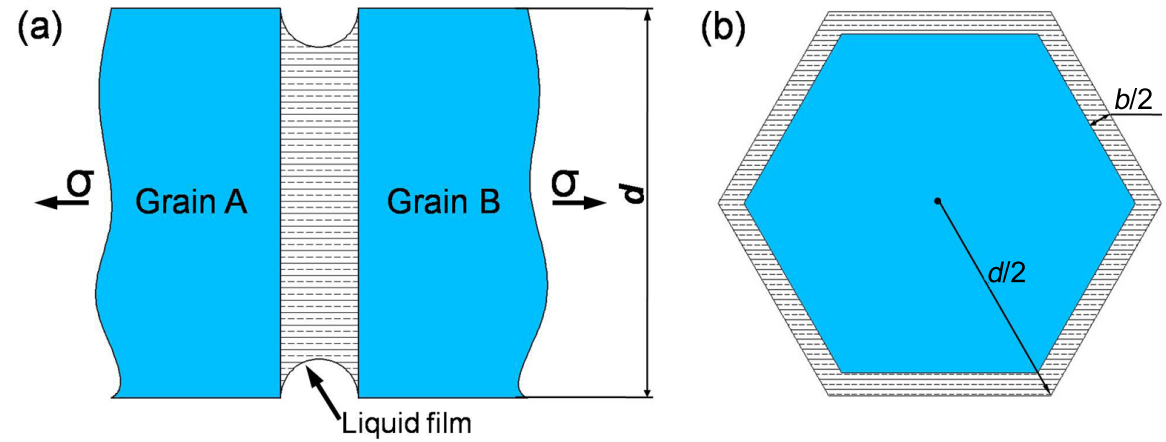

Fig. 8 Calculation of $\sigma_{\text {crack }}$ : (a) model for two grains separated by a liquid film; (b) elementary unit of idealized mushy zone microstructure of alloy

As indicated by Eq. (3), $\sigma_{\text {crack }}$ increases when the grain size $(d)$ decreases or the solid fraction increases. So the refinement of alloy microstructure and rising of $f_{\mathrm{s}, \mathrm{crack}}$ caused by $\mathrm{Zr}$ addition decreases the liquid film thickness and thus increases the fracture stress of liquid film, which means the improvement of the tensile strength of semi-solid alloy. As hot tearing onset occurs through tensile fracture of the semi-solid alloy, the increased liquid film fracture stress will surely improve the hot tearing resistance of alloys. So the hot tearing susceptibility of WE54 alloy decreases after Zr addition.

\section{Conclusions}

Hot tearing behavior of sand cast WE54 alloy with and without $\mathrm{Zr}$ addition was investigated based on measurement of hot tearing onset temperature and $T-f_{\mathrm{s}}$ data. The hot tearing formation procedure is explained, and the effects of $\mathrm{Zr}$ addition on hot tearing behavior of WE54 alloy are discussed. Finally, the following conclusions are reached:

(1) Hot tearing onset occurs at relatively low solid fraction in sand cast WE54 alloy (0.47 in Zr-free alloy, 0.74 in Zr-containing alloy), indicating that a significant amount of interdendritic liquid is still present at hot tearing onset. The fracture stress under which hot tearing onset occurs $\left(\sigma_{\text {crack }}\right)$ is about $0.5 \mathrm{MPa}$ in Zr-free alloy and about 1.0 MPa in $\mathrm{Zr}$-containing alloy.

(2) During casting solidification, interdendritic liquid flows between solidifying dendrites to coordinate with the contraction strain before hot tearing onset and forms interdendritic liquid films. The interdendritic liquid films are separated under contraction stress and form hot tearing defects.

(3) The microstructure of WE54 alloy is significantly refined by $\mathrm{Zr}$ addition, and the solid fraction at hot tearing onset $\left(f_{\mathrm{s}, \text { crack }}\right)$ increased after $\mathrm{Zr}$ addition. These changes contribute to the increasing of fracture stress $\left(\sigma_{\text {crack }}\right)$ of interdendritic liquid films, so the hot tearing susceptibility of WE54 alloy declines after $\mathrm{Zr}$ addition.

\section{Acknowledgements}

This work was financially supported by the National
Basic Research Program of China (No. 2013CB632202)

\section{REFERENCES}

[1] G.H. Wu, Y. Zhang, W.C. Liu and W.J. Ding, J. Magnesium Alloys 1 (2013) 39.

[2] X. Li, W. Qi, K. Zheng and N. Zhou, J. Magnesium Alloys 1 (2013) 54.

[3] T. Li, K. Zhang, X.G. Li, Z.W. Du, Y.J. Li, M.L. Ma and W.J. Ding, J. Magnesium Alloys 1 (2013) 47.

[4] A.A. Luo, J. Magnesium Alloys 1 (2013) 2.

[5] D. Fabregue, A. Deschamps, M. Suery and J.M. Drezet, Acta. Mater. 54 (2006) 5209.

[6] A.B. Phillion, S.L. Cockcroft and P.D. Lee, Mater. Sci. Eng. A 491 (2008) 237.

[7] L. Bichler and C. Ravindran, Mater. Des. 31 (2010) S17.

[8] D. Fabregue, A. Deschamps, M. Suery and H. Proudhon, Scr. Mater. 59 (2008) 324.

[9] P.D. Lee, A.B. Phillion and S.L. Cockcroft, Scr. Mater. 55 (2006) 489.

[10] A.M. Nabawy, A.M. Samuel, F.H. Samuel and H.W. Doty, J. Mater. Sci. 47 (2012) 4146.

[11] M.O. Pekguleryuz, S. Lin, E. Ozbakir, D. Temur and C. Aliravci, Int. J. Cast Met. Res. 23 (2010) 310.

[12] H.K. Kamga, D. Larouche, M. Bournane and A. Rahem, Mater. Sci. Eng. A 527 (2010) 7413.

[13] R.N. Esfahani and B. Niroumand, Mater. Charact. 61 (2010) 318.

[14] M. Li, H.W. Wang, Z.J. Wei and Z.J. Zhu, Mater. Des. 31 (2010) 2483

[15] S. Li, K. Sadayappan and D. Apelian, Int. J. Cast Met. Res. 24 (2011) 88.

[16] Y.S. Wang, W.J. Ding, Q.D. Wang and Y.P. Zhu, Acta. Metall. Sin. 37 (2001) 527. (in Chinese)

[17] G. Cao, I. Haygood and S. Kou, Metall. Mater. Trans. A 41 (2010) 2139.

[18] G. Cao, C. Zhang, H. Cao, Y.A. Chang and S. Kou, Metall. Mater. Trans. A 41 (2010) 706.

[19] D.G. Eskin, Suyitno and L. Katgerman, Prog. Mater. Sci. 49 (2004) 629.

[20] S. Thompson, S.L. Cockcroft and M.A. Wells, Mater. Sci. Technol. 20 (2004) 194.

[21] Q. Ma and D.H. Stjohn, Int. J. Cast Met. Res. 22 (2009) 256.

[22] D.J. Lahaie and M. Bouchard, Metall. Mater. Trans. B 32 (2011): 697.

[23] C.H. Dickhaus, L. Ohm and S. Engler, AFS Trans. 101 (1993) 677. 